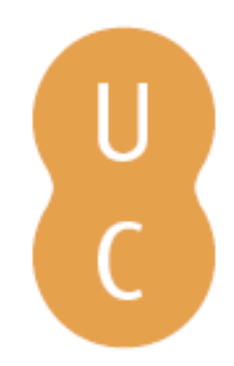

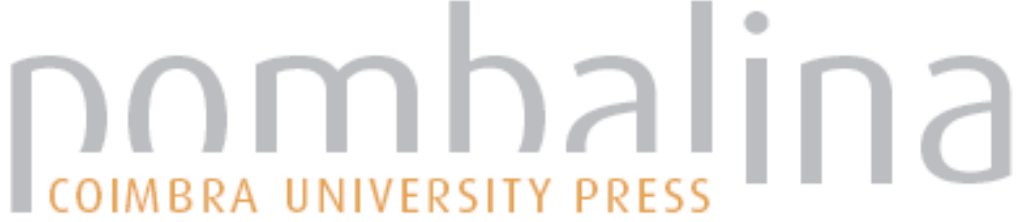

\section{Una mujer de un tiempo distinto: La Fedra (1984) de Lourdes Ortiz}

\author{
Autor(es): López, Aurora
}

Publicado por: Imprensa da Universidade de Coimbra; Annablume

URL

persistente: URI:http://hdl.handle.net/10316.2/40916

DOI: $\quad$ DOI:https://doi.org/10.14195/978-989-26-1298-0_10

Accessed : $\quad$ 26-Apr-2023 11:31:56

A navegação consulta e descarregamento dos títulos inseridos nas Bibliotecas Digitais UC Digitalis, UC Pombalina e UC Impactum, pressupõem a aceitação plena e sem reservas dos Termos e Condições de Uso destas Bibliotecas Digitais, disponíveis em https://digitalis.uc.pt/pt-pt/termos.

Conforme exposto nos referidos Termos e Condições de Uso, o descarregamento de títulos de acesso restrito requer uma licença válida de autorização devendo o utilizador aceder ao(s) documento(s) a partir de um endereço de IP da instituição detentora da supramencionada licença.

Ao utilizador é apenas permitido o descarregamento para uso pessoal, pelo que o emprego do(s) título(s) descarregado(s) para outro fim, designadamente comercial, carece de autorização do respetivo autor ou editor da obra.

Na medida em que todas as obras da UC Digitalis se encontram protegidas pelo Código do Direito de Autor e Direitos Conexos e demais legislação aplicável, toda a cópia, parcial ou total, deste documento, nos casos em que é legalmente admitida, deverá conter ou fazer-se acompanhar por este aviso. 


\section{O Livro do Tempo: \\ Escritas e reescritas}

\section{Teatro Greco-Latino e sua recepção II}

Maria de Fátima Silva, Maria do Céu

Fialho \& José Luís Brandão (coords.)

IMPRENSA DA UNIVERSIDADE DE COIMBRA 


\title{
UNA MUJER DE UN TIEMPo Distinto: LA FEDRA (1984) DE Lourdes Ortiz
} (A woman from a different time: Phaedra (1948) by Lourdes Ortiz)

\author{
Aurora López (auroral@ugr.es) \\ Universidad de Granada
}

\begin{abstract}
Resumen - La publicación en el año 2013 de la pieza teatral Fedra de Lourdes Ortiz (Madrid, 1943), estrenada en Sevilla muchos años antes, en 1984, pone en nuestras manos una visión muy particular del tema trágico del amor de Fedra e Hipólito, convertido por la novelista y dramaturga madrileña en una parodia cómica, que desmitifica y desdramatiza por completo el tema tradicional.

Palabras clave - Lourdes ortiz, Fedra, tragedia, parodia cómica.
\end{abstract}

Aвstract - The publication in 2013 of the play Phaedra of Lourdes Ortiz (Madrid, 1943), premiered in Seville many years before, in 1984, puts in our hands a very particular view of the tragic theme of Phaedra's and Hippolytus love, converted by the well-known novelist and playwright from Madrid in a comic parody, which demythologizes the traditional theme and changes completely its tragic nature.

KeYwords - Lourdes Ortiz, Fedra, tragedy, comic parody.

\section{Una edición esperada}

En los últimos meses del año 2013 apareció la edición de $F_{e d r a}{ }^{1}$, de la conocida narradora, dramaturga y ensayista Lourdes Ortiz (Madrid, 1943), una obra teatral que se había estrenado muchos años antes, en concreto en 1984, en el Teatro Lope de Vega de Sevilla, y cuya existencia conocíamos al menos quienes nos dedicamos al estudio del teatro antiguo y su pervivencia en los teatros contemporáneos gracias a un análisis de cierto detalle que le había dedicado María José Ragué en su excelente e ilustrativo libro Lo que fue Troya ${ }^{2}$, la cual había podido conocer la obra inédita gracias a una copia del original facilitada por su autora. Mi curiosidad por esta Fedra de Ortiz era grande, debido sobre todo al hecho de que Ragué la presentaba en el lugar referido como una reescritura interesante, de notable modernidad, pero también por la atracción que suscita una escritora actual que, como es el caso de Lourdes Ortiz, ha escrito muchas obras situándolas en el mundo clásico grecolatino: en el teatro Penteo ${ }^{3}$, Dido en los infiernos (1996), en la novela La liberta (1992), en el relato corto Los motivos de Circe (1988), etc.

\footnotetext{
${ }^{1}$ Ortiz, L. (2013), Fedra. Madrid: Ediciones Irreverentes.

${ }^{2}$ Ragué Arias 1992: 129-134.

3 Todavía inédito; estudiado también por Ragué Arias 1992: 127-129.
} 
Uno de los primeros aspectos de la Fedra de Lourdes Ortiz que llama nuestra atención es la novedad de su planteamiento general y de abundantes recursos, en especial si la comparamos con otras reescrituras españolas del tema de Fedra e Hipólito producidas en nuestro siglo. Es algo que ha explicado muy bien Ragué en el comienzo de su análisis antes aludido, que me permito reproducir a continuación:

El mito de Fedra es reivindicación del placer y de la libertad sexual. El tratamiento del personaje, en épocas anteriores, sólo podía hacer de Fedra un personaje monstruoso y negativo. A comienzos del siglo, Unamuno daría a Fedra un carácter maternal y un arrepentimiento católico que la humanizaría. Julián Gallego le daría cierta elegancia capaz de limar su agresividad como mujer atípica en la sociedad de la época. Gil Novales la desmitifica para darle carácter de parábola política en clave de parodia cómica con elementos de teatro del absurdo. Domingo Miras hace de Fedra un personaje positivo arquetipo de la madre en una sociedad matriarcal, comunismo primitivo en el que la escala de valores es distinta y opuesta a la de la sociedad contemporánea. Pero la utilización más característica del personaje es la que lo convierte en símbolo de libertad sexual, en reivindicación de Fedra de un compañero de lecho de su edad. En España hay que llegar a la década de los 80 para que esta lectura s e a posible.

Manuel Martínez Mediero escribe una Fedra feminista y coyuntural para ser estrenada en 1982 en el escenario del teatro romano de Mérida, una Fedra en tono irónico y lenguaje coloquial, de personajes emblemáticos y sin profundidad que quiere decirnos que el mundo podría salvarse por el amor en libertad que representa Fedra y que constituye un discurso banal sobre el poder y la libertad, que pese a su dinamismo, su comicidad y su lenguaje esporádicamente bello, no deja de ser una obra coyuntural que busca el éxito del momento en Mérida, en 1982.

Será la Fedra de Lourdes Ortiz la primera versión del personaje que le dará las características del mito clásico. Fedra rompe el tabú del incesto pero sobre todo reivindica el amor en libertad, el placer sexual y reclama un compañero de lecho de su edad. La Fedra de Ortiz nos dirá que "la androginia es un modo nuevo y más completo de vida”. Y, lógicamente, aquí también, como en Penteo, el tema de la homosexualidad será elemento importante de la obra (129-130).

\section{UNA REESCRITURA NOVEDOSA}

La edición de que ahora disponemos de Fedra presenta algunas particularidades que, en cierto modo, dificultan inicialmente su estudio. Para empezar,

\footnotetext{
${ }^{4}$ Sobre todas estas reescrituras del tema de Fedra e Hipólito, sus fechas de composición, estreno y publicación, cf. Pociña, López 2016: 11-27.
} 
carece de la habitual lista de personajes conocida como "Reparto", lo cual plantea un primer problema: en la primera página, se encuentra la didascalia de estreno en 1984, en el Teatro Lope de Vega de Sevilla; de su lectura deducimos que actuaron cinco personas, con el recurso, de muy antiguo cuño, de representar algunas varios papeles no fundamentales; pues bien, lo curioso es que no encontramos entre los papeles señalados el nombre de Teramenes, que aparecerá en la Esc. II; vemos, en cambio, un personaje designado como La feminista, que obviamente tendremos que identificar con "Mujer" en la Esc. VII; nada se señala, en fin, acerca de los Niño 1 y Niño 2, “dos chavales con pantalón corto", que interpretarán la Esc. VI. También resultan muy escasas las acotaciones, echándose de menos la muy habitual del comienzo, con indicación local y temporal del desarrollo del asunto. No hay, en fin, ningún tipo de prólogo o introducción, en el que Lourdes Ortiz nos haga conocer sus planteamientos generales sobre su reescritura de un tema clásico tan frecuentemente llevado a escena en nuestro tiempo, ni sobre sus hipotextos clásicos, que sin embargo veremos aparecer alguna vez en el texto literario de la obra.

\section{SituACión TEMPORAL Y LOCAL}

A pesar de no darse explicaciones, según acabo de decir, Lourdes Ortiz nos trae a un tiempo moderno, actual, ya en las palabras con que abre Fedra la Esc. I:

Es chiquito como el ámbar gris y jugoso, dulce y agrio como los cepillos de dientes, flexible y ágil como las antenas de televisión, que gimen asustadas de su propia belleza sobre los tejados de la ciudad (7).

A continuación, hablando con Enona, en su deseo ansioso de que Hipólito venga de nuevo a estar con ella esta noche, Fedra expresa sus sentimientos recurriendo a la pasión de García Lorca, que, en efecto, tendrá una presencia claramente rastreable a lo largo de toda la obra:

Fedra - Sí vendrá, dueña; sí vendrá.

Sabes, dueña, me pongo lorquiana cuando pienso en él, se me revuelven las entrañas y me galopan corceles de crines negras en la cintura.

Enona - En la cintura. ¡Ya te daba yo, ya! A eso yo lo llamo de otra manera. Pero no son palabras para una casa respetable.

Fedra - ¡Ay, dueña! Cuando galopa sobre mis espaldas, cuando pone espuelas sobre mi vientre, crea cruces de tomillo que florecen como candelas encendidas (7).

Un tiempo actual, en un ambiente marcadamente andaluz, lorquiano, con connotaciones tradicionales, profundamente arraigadas en las vivencias de 
quienes tenemos cierta edad y cierta cultura. De este modo, Fedra compara su encuentro amoroso con Hipólito con la Anunciación a la Virgen María de la tradición religiosa cristiana:

Fedra - Él vino a mí y me dijo: "Bendita tú eres entre todas las mujeres", y aún puedo percibir el resplandor luminoso de sus rayos dorados al atravesar la habitación. Y yo sólo pude inclinar la cabeza, cruzar las manos y dije "Hágase en mí” (8).

Esta situación temporal y local podría servir para hacer una edición anotada del drama de Lourdes Ortiz, en el que a menudo descubrimos elementos que lo acercan a realidades de nuestras vidas, propiciando una relación afectiva más estrecha, no sentida en reescrituras precedentes. Veamos un ejemplo: al final de la Esc. IX, Personajillo A y Personajillo B, dos figuras en apariencia de relleno, pero que en realidad actúan como Coro con frecuencia a lo largo de toda la obra, mantienen este diálogo:

Personajillo B - Pero eso del amor es muy antiguo. Una cosa de las abuelas. Yo creo que la mía, por ejemplo, se enamoró una vez de un teniente.

Personajillo A - Y el teniente tenía una novia en cada puerto.

Personajillo B - No lo sé. Pero mi abuela cantaba canciones. Había una que decía:

Cuando rezo por la noche

en mi alcoba.

Le pregunto a la estatuilla de la Virgen...

Personajillo A - ¿Y qué tiene que ver la Virgen con todo esto?

Personajillo B - No, no. La Virgen no. Pero luego dice:

Gitanillo, gitanillo, gitanillo...

Personajillo A - Agua que no has de beber...

Personajillo B - Ya quisiera yo beber como ellos beben. (56-57)

En realidad, los dos Personajillos han mezclado dos cuplés de rancio abolengo, muy conocidos en las primeras décadas de la segunda mitad del siglo $\mathrm{XX}$, titulados "Agua que no has de beber" y "Mala entraña"; si no se conocen desconociendo estas canciones populares, hay que pensar que no se alcance por completo el sentido del diálogo.

Más significativa es la localización andaluza, más bien castizo-gitana, de la escena XI, en la que el final tradicional de Hipólito es reproducido en una intervención, ajena al resto de la obra, de una Gitana y un Gitano, en presencia de Fedra; el final trágico de este Gitano-Hipólito evoca el desenlace trágico originario en una reescritura en la que, como más adelante veremos, el argumento se resuelve de una forma feliz, absolutamente anti-trágica, propia de una auténtica comedia. 


\section{Los PERSONAJES}

Los personajes centrales de la Fedra de Ortiz, son, como en las tragedias de Eurípides y de Séneca, Fedra, Hipólito y Teseo, tan reelaborados por la dramaturga que no resulta productivo establecer comparaciones detalladas; acaso sería posible afirmar que la autora ha estado acertada en dar a su reescritura el nombre de Fedra, al modo de Séneca primero y mucho después Racine, precedentes tenidos en consideración, y no el de Hipólito, al modo de Eurípides, que no resulta desde luego protagonista de la trama, a pesar de tener un papel destacado en su desarrollo.

Fedra, la indudable protagonista, rompe por completo con los prejuicios, consideraciones morales, juicios ajenos, que puedan oponerse a su amor sin límites por Hipólito, el hijo de su marido, con el que, desde el comienzo, sabemos que ha tenido más de una relación sexual plena, y al que espera noche tras noche, pues él no viene siempre. A Enona, que la acusa de delirio, le contesta contundentemente:

Fedra - Es la fiebre, dueña. la fiebre que nos une tarde tras tarde, noche tras noche; la fiebre que provoca inundaciones en el lecho, que hace estallar miles de estrellas encendidas, como dardos que aguijonean la carrera de las piernas, el aleteo de los brazos. Él, abeja solicita que derrama su néctar sobre los pétalos siempre abiertos y preparados para recibirle, él (9).

En su despreocupación total por todo aquello que no sea su disfrute sexual con su hijastro, esta Fedra nos resulta lejanísima de la dama enferma de amor que vemos de forma pasajera en el Hipólito de Eurípides y de la mujer antiprototípica que traza Séneca; ahora, tantos siglos después, con tantos prejuicios superados, la nueva Fedra es capaz de referirse sin el menor recelo a su pasión por Hipólito, sorprendiéndonos por ejemplo en una conversación taimada y engañosa con su marido Teseo, que tontamente aparenta no enterarse de nada de la realidad de la que es víctima:

Fedra - Hipólito se parece mucho a ti.

Teseo - Sí, pero es un poco más...

Fedra - ¿Más qué?

Teseo - No sé, supongo que somos bastante distintos. Tiene algo de su madre. Era melancólica; pero ya te he hablado muchas veces de ella. Le faltaba tu fuerza.

Fedra - Hipólito la tiene.

Teseo - Puede ser. Yo todavía no se la he visto. Quizá he sido con él excesivamente blando. Ha estado mucho tiempo entre mujeres.

Fedra - Por eso se aparta de ellas.

Teseo - ¿Es injusto contigo? 
Fedra - No, conmigo no. Conmigo...

Teseo - Menos mal que te encontré. En ti Hipólito pudo encontrar una madre. Fedra - Yo no soy una madre para Hipólito.

Teseo - Esas son manías. Claro que has sido y eres una madre. Él siempre te ha considerado así. ¿Crees que si yo no estuviera convencido de que te quiere mucho, me atrevería a reclamarle para que te hiciera compañía? Hipólito te adora y creo que te lo mereces.

Fedra - Yo también lo adoro a él.

Teseo - Ya sé que siempre le has tratado como si fuera tu propio hijo.

Fedra - No como a mi propio hijo. Como a ti mismo.

Teseo - Bueno, como a mí mismo. Siempre fuiste generosa y no es fácil que una esposa acepte al hijo de otra como tú aceptaste a Hipólito.

Fedra - Lo difícil sería no aceptarle... (42-43)

Hipólito, por su parte, se define él mismo perfectamente, al comienzo de la Esc. II, por medio de una ruptura de la ilusión escénica con un soliloquio metateatral, en el que se compara con los Hipólitos de las tragedias de Eurípides, Séneca y Racine. Dejémosle autopresentarse:

Hipólito - ¿Lo saben ya? Yo, el chivo expiatorio, yo el bueno, el incorruptible, el casto. Yo también conozco las versiones anteriores y tengo que prepararme para lo peor. Y sin embargo, siento defraudarles; no sé cómo será el final, pero sí sé una cosa que a ustedes no va a gustarles demasiado, y es que a mí, Hipólito, en este caso y frente a todas las predicciones -son cosas de los tiempos, supongo- me encanta mi madrastra, en realidad me vuelve loco. Es como. ¡Que me perdone Diana! Ni amo los bosques, ni me chifla la Naturaleza. Me encanta la ciudad, me pirra el humo de las fábricas y los automóviles, me gusta el metro, el sudor, el olor a tabaco de las discotecas, las multitudes apretadas. ¡Ah, la poesía de los rascacielos apelmazados, chorreando el tizne de las máquinas! Me enloquecen los aparatos electrónicos, los ordenadores, las luces. Ya lo ven. Sólo hay una cosa en la que coincido con mis antecesores. Bueno, y si lo pienso un poco, ni siquiera en eso. Me refería a mi padre; no es que no quiera al viejo, no, ¿cómo no iba a quererle? Pero ni me interesan sus asuntos, ni me quita el sueño su dinero, ni me preocupa su política, ni tampoco creo en sus posturas de triunfador y de hombre de mundo (12).

Este Hipólito urbano, tan diferente, responde sexualmente a las demandas de Fedra, pero ello no impide que tenga habituales relaciones homosexuales, claramente con su amigo Teramenes, abiertamente con el Camarada que aparece en la Esc. VII, y con otros muchos, según indica Enona cerca del final, cuando a la afirmación de Fedra "Hipólito me quiere como antes", contesta lisa y llanamente "Y te comparte con veinticinco" (65). En el personaje concebido por Ortiz desaparece el Hipólito misogino, pero aflora el más o menos subyacente Hipólito homosexual, como vemos abiertamente en la Esc. VII: 
Camarada - ¿Quieres que juguemos a cualquier cosa? ¡Ay, Hipólito!: la medida, el canon, la belleza, el orden, la luz, la razón; todo es masculino. Por cierto, que tú no desentonas. Con que te mires al espejo me darías la razón. La curva ¡Puaj!, la cueva ¡Puaj! Lo nuestro es la acción, la fuerza. A mí me chiflan las motos y a ti los caballos. Ejercicio, dominio.

Hipólito -Tengo varios proyectos, se me ocurren cosas. Mi cabeza es como una marmita.

Camarada - ...en ebullición, como la mía. Lo nuestro es la creación. Ellas producen crías, nosotros creamos. Todo el orbe es obra nuestra, tuya y mía. Lo único que cuenta, Hipólito: la amistad... ágape... A eso los griegos lo llamaban amor. Ellas son imperfectas, nosotros, y no creo que tenga que ponerme grosero, autosuficientes. ¿Tú me entiendes, no?

Hipólito - Si, yo entiendo.

Camarada - La androginia es un modo nuevo y más completo de vida. ¿Supongo que estarás de acuerdo?

Hipólito - Sí, creo que estoy de acuerdo. La fratría, la caza, la guerra, el juego ¿va por ahí, no?

Camarada - Más o menos. Tú y yo por ejemplo, lo tenemos todo. Sólo nos falta llegar al momento supremo de la fusión, a la culminación, donde uno mismo se encuentra con uno mismo. El beso de Narciso reflejándose en las aguas. Tú eres mi reflejo, yo soy el tuyo. (36-37)

El tercer gran personaje tradicional de la leyenda, Teseo, tiene una presencia nada desdeñable en la nueva versión, pero Ortiz no le ha dedicado un tratamiento especial, semejante a los casos de Fedra y de Hipólito. Teseo es un marido preocupado por Fedra, un padre preocupado por Hipólito, pero no se entera para nada de sus problemas amorosos, que tanto le afectan a él. En la Esc. XII, donde la autora nos lo presenta jugando a las cartas con un amigo, asistimos a una excelente recreación del personaje típico del cornudo simplón, que no entiende para nada las alusiones, llenas de malicia, que le hace ese amigo sobre la sospechosa relación entre Fedra e Hipólito. Y como el desenlace de Fedra será completamente distinto del trágico habitual, Teseo llegará a él sin grandes problemas, sin mucha pena ni mucha gloria.

De los personajes restantes, tienen cierto relieve y, desde luego, nombre propio, de clara procedencia raciniana, Enona y Teramenes. El primero de ellos, Enona, castellanización obvia de Oenone, la nodriza de Fedra en el drama de Racine $^{5}$, corresponde muy bien a la descripción que de ella hacía el dramaturgo francés en su Reparto: "nourrice et confidente de Phèdre"; dado el anacronismo que significaría ponerle una nodriza a Fedra en tiempos modernos, Enona será la íntima confidente de Fedra, su amiga inseparable y su consejera; sin

\footnotetext{
${ }^{5}$ Sigo la edición Racine 1931.
} 
embargo, como en la reescritura de Ortiz la relación entre Fedra e Hipólito es cosa conocida desde el comienzo, la "dueña" (así le llama Fedra) no va a tener el importante papel que desempeña primero en Eurípides, después en Séneca, como intermediaria en los amores de Fedra por su hijastro.

Teramenes carece de precedente en el tragediógrafo griego y en el latino; Racine lo incorpora en su Phèdre como "gouverneur d'Hippolyte", según la indicación del Reparto. En el drama francés, su papel resulta verdaderamente interesante: en primer lugar, en el Acto primero Esc. 1, en diálogo con Hipólito, del que resulta guía y consejero comprensivo, función que mantendrá a lo largo de la obra; desde el punto de vista dramático, además destaca su difícil cometido en el Acto V Esc. 6, en la larga tirada de 72 versos (1498-1570) en que narra a Teseo el desgraciado final de Hipólito, a semejanza de los prolijos relatos del Mensajero en el Hipólito de Eurípides (1173-1254) y en la Fedra de Séneca (10001114). En la reescritura de Ortiz, Teramenes no ocupa un papel tan relevante como en Racine, ni mucho menos; para empezar, su función es distinta, pues no se presenta como el ayo y sensato consejero de Hipólito, sino como uno de sus amigos, un joven superficial, divertido, con el que mantiene diversiones de todo tipo, que alternan con sus relaciones con Fedra:

Teramenes - La escena primigenia: Papá viola a mamá, yo quiero ser papá. ¿Por qué no te dedicas a lo de siempre? He visto Edipos mal digeridos, pero el tuyo...

Hipólito - Edipo no. Esto no es Edipo, esto es muy fuerte.

Teramenes - Por eso.

Hipólito - ¿Por qué no te ocupas del tuyo?

Teramenes - ¿De qué?

Hipólito - De tu Edipo. Cada cual se lo resuelve como puede: tú con tus amiguitos, el otro con su novia tan seriecita, y yo...

Teramenes - Con tu mamaíta.

Hipólito - Fedra no es mi madre.

Teramenes - Ya, pero es la mujer de tu padre. Viene a ser lo mismo.

Hipólito - Cada vez que le pone la mano encima...

Teramenes - Lo que te fastidia es pensar que tal vez tiene más experiencia.

Los maduritos no se lo hacen mal. Necesitan estimulantes pero...

Hipólito - ¡Cállate!

Teramenes - Estás hecho un muermo y yo me largo. Cuando quieras volver, estamos donde siempre. (24-25)

La relación de amistad, por así llamarle, entre Hipólito y Teramenes se mantendrá siempre, como un elemento más para definir una situación de libertad en los comportamientos sexuales que explica los cambios experimentados en la historia dramatizada. En la salida ya hacia el desenlace, en la Esc. XIII, Fedra explica con todo desenfado: 
Fedra - ...Enona, ¿̇sabes que Hipólito ha prometido presentarme a sus amigos? Cualquiera de estas noches vendrá Teramenes. Me habla tanto de él que ya casi le conozco como si yo misma fuera Hipólito. Es un muchacho encantador, sensible, delicado, inteligente. Hipólito le adora y yo ya sabes que adoro todo lo que adora Hipólito.

Enona - Donde caben tres, caben cuatro. Esperemos que a Teramenes le gusten también los alhelíes. (63-64)

De los personajes restantes, que no cuentan con nombre propio, adquiere un relieve especial la denominada Mujer, que ocupa junto con Hipólito toda la Esc. VII para impartir toda una lección de sexualidad desde su ideología feminista militante. Su primer parlamento plantea claramente su forma de pensar y sus reivindicaciones:

Mujer - Pareces muy joven y antes de que digas nada, tengo que darte algunas lecciones: ante todo igualdad, querido. Tú y yo somos iguales. ¡Qué yo tengo y tú no y que tú tienes y yo no! Eso es lo de menos, reducto de una ideología burguesa y decadente que dictamina que el poder, vuestro poder, reside en el faaalo. ¡Aaay, se me llena la boca al decirlo! ¡Así sois todos, prepotentes, machistas, desaprensivos, explotadores, y en el fondo impotentes! ¿Podrás creerte que últimamente no consigo encontrar uno sólo que funcione bien? El sexo, querido mío, es un arte, o más bien una práctica... una práctica tan sana y tan necesaria como el comer. Yo por lo menos, un día sí y otro no, si no me pongo inaguantable, insoportable, te lo juro. Pero ¡luego te llevas cada chasco! Porque en esto, como en todo, se trata de saber, de combinar la técnica, vamos. Y vosotros, mal acostumbrados como estáis os creéis que podéis seguir aprovechándoos de nosotras. Pero no, rico, jeso se ha acabado! Yo soy tan dueña de mi goce como tú lo eres del tuyo. Repite conmigo: ¡La mujer es mi igual! ¡La mujer es tan hombre, como yo soy hombre! La culpa, en el fondo la tiene el lenguaje. Deberíamos utilizar un género neutro (31-32)

Menor importancia tienen el Camarada de Hipólito que aparece en la Esc. VII, al que ya he tenido ocasión de aludir; la Gitana y el Gitano que representan en la Esc. XI un desenlace trágico de la trama, semejante al tradicional; el Amigo de Teseo que juega con él a las cartas en la Esc. XII. Son personajes sin interés propio, pero que sirven a Lourdes Ortiz para perfilar aspectos de personajes importantes, o para complementar su visión general de la obra. Esta multiplicidad no le plantea problemas a la autora: como experta indudable en la praxis teatral, sabe que puede recurrir con facilidad a la interpretación de varios papeles no centrales por un mismo actor o actriz. De hecho, en el estreno de Fedra en el año 1984, en Sevilla, Lourdes Ortiz, que dirigía la representación, confiaba a la actriz Marta Barco los papeles del Personajillo A, Enona, La 
feminista y La gitana, mientras que el actor Jesús Prieto desempeñaba los del Personajillo B y El camarada 6 .

Un papel de mayor consideración es el que desempeñan Personajillo A y Personajillo B, émulos del Coro en las tragedias antiguas, pero que precisamente sirven para diluir el carácter posiblemente trágico del desarrollo argumental, hasta que al fin, en la Esc. XII y la Esc. XIII representen un papel fundamental a la hora de transmutar el género dramático de la Fedra de Lourdes Ortiz de una tragedia en una comedia.

\section{Alusiones a las Versiones ANTERiores}

De las incontables versiones teatrales, narrativas o poéticas que a partir de la más antigua conservada, el Hipólito (portador de la corona), estrenada por Eurípides ${ }^{7}$ en el año 428 a. C., han tratado de diversas maneras la historia de Fedra e Hipólito, hasta la estrenada por Lourdes Ortiz en 1984, nuestra dramaturga muestra señales obvias, y ofrece además pruebas abiertas, de haber tenido presentes tan solo tres: el referido Hipólito de Eurípides, la Fedra de Séneca, la Phèdre de Racine, no sé si en su original francés, o en alguna de las varias traducciones, generalmente muy aceptables, existentes en español ${ }^{8}$. Tampoco puedo asegurar que no conociese la Fedra de Miguel de Unamuno, si bien no he conseguido encontrar huella alguna aparente del drama de nuestro gran filósofo. En cambio, teniendo en cuenta la edad de Lourdes Ortiz y su movida biografía en los ámbitos literarios y artísticos de los años 60 y 70, me atrevo a conjeturar (me gustaría poder preguntárselo) que conociese dos películas, muy importantes en su momento: la Fedra (1956) dirigida por Manuel Mur Oti, con intrerpretación de Emma Penella, Vicente Parra y Enrique Diosdado en los papeles correspondientes a los clásicos Fedra, Hipólito y Teseoª y la Phaedra (1962) dirigida por Jules Dassin, con Melina Mercouri, Anthony Perkins y Raf Vallone en los tres papeles fundamentales ${ }^{10}$.

Ortiz, según ya he referido más arriba, juega metateatralmente con sus modelos, cuando Hipólito se autopresenta en la Esc. II, comparándose con el

${ }^{6}$ Datos que constan en la primera página de la edición de Fedra, Madrid, 2013. Sin embargo, la lista no está completa, lo que me hace pensar que es muy posible que Lourdes Ortiz prescindiera en aquella ocasión de algunos pasajes del texto definitivo, en concreto de las escenas XI y XII (la Gitana y el Gitano; el juego de cartas de Teseo con el Amigo). He realizado la prueba de seguir el conjunto sin esos tres personajes, y la obra prácticamente no se resiente.

${ }^{7}$ Cf. Pociña, López 2016: passim.

${ }^{8}$ Cf. por ejemplo: Racine 1944, 1982, 1999.

${ }^{9}$ Cf. Salvador Ventura 2008: 503-524; cf. también Mariño Sánchez-Elvira 1997: 111-125; Mariño Sánchez-Elvira 1997: Metakinema www. metakinema.es/metakineman0s1a1.htm1

${ }^{10}$ Cf. Lavagnini, R. (2003), “Fedra al cinema”, Dioniso: 242-245; Salvador Ventura 2008; Rubino, M. (2009), "Margarita Liberaki”, in Rubino, M., Fedra per mano femminile. Genova, Il melangolo: 67-73. 
personaje de "versiones anteriores", en las cuales quedan aludidas las de Eurípides, Séneca y Racine. El recurso, verdaderamente sorprendente, resulta un hallazgo.

No menos sorprendente es, poco después, una cita directa de la Fedra de Séneca, en la Esc. III:

Personajillo B - No, no es su hijo; pero como si lo fuera; es el hijo del marido. Personajillo A - ¿Y qué?

Personajillo B - Pues eso. ¡Un lío! Lo decía Séneca: “¿Te propones confundir los tálamos del padre y del hijo y concebir en tus flancos una prole mezclada? Personajillo A - Pero esta Fedra no tiene problemas. Toma anticonceptivos. Luego lo de la prole son pamemas. (20)

El pasaje es fácilmente localizable: se trata de una pregunta de la Nodriza a Fedra, 171-172: miscere thalamos patris et gnati apparas / uteroque prolem capere confusam impio? ?1. $^{11}$

En la Esc. 4 de nuevo se rompe la ficción escénica, recordando el estilo grandilocuente de uno de los precedentes, Racine. Ante un comentario de Teramenes sobre la forma extraña de hablar Hipólito, éste le contesta: "Necesitaría que Racine me diera el tono preciso. Cuando quiero ponerme apasionado, caigo en la cursilería" (23).

En la Esc. 12, cuando los personajillos del coro proyectan qué debe hacerse con Fedra y con los demás personajes, según pronto comentaré, Personajillo A recuerda que murieron suicidándose "La de Eurípides, la de Séneca. Todas tuvieron una muerte honrosa" (60). En su absoluta independencia con respecto a sus hipotextos, se nota que a Lourdes Ortiz le ha parecido un recurso simpático, tal vez por totalmente inusual, poner en boca de sus personajes el nombre de los tres grandes dramaturgos-modelo.

\section{Desmitificación TOTAL. Destrucción dE La TRAgEdia}

Desde el primer momento del desarrollo de la trama, nuestra autora va preparando el camino de una desmitificación total de la multisecular leyenda del enamoramiento de Fedra de su hijastro Hipólito. Alejándolos del incierto tiempo mítico, Ortiz los trae a un tiempo actual, a su tiempo, la controvertida década de los años 80 del siglo pasado, que ella trata con toda desenvoltura, con absoluta carencia de perjuicios, tal como lo hace por ejemplo en las atrevidas páginas de su novela Antes de la batalla, escrita algún tiempo después que Fedra ${ }^{12}$.

\footnotetext{
${ }^{11}$ No he conseguido identificar la procedencia de esta versión entre las diversas traducciones impresas; pienso que es posible que se deba a la propia Lourdes Ortiz.

${ }^{12}$ Ortiz 1992.
} 
Puesta a desmitificar, Ortiz conserva la base argumental, que resulta ser un amor inconveniente, socialmente inconveniente, familiarmente inconveniente, políticamente inconveniente: una madrastra y un hijastro. Sin embargo, la fuerza trágica se pierde ya desde el comienzo, pues en el punto de partida Fedra ya tiene una relación sexual completa con Hipólito, punto al que jamás se llegaba en las versiones clásicas: no olvidemos que Eurípides nunca juntaba a los dos personajes en una misma escena. De este modo, el argumento nos hará asistir a una normalización progresiva, por así decirlo, de la relación sexual, en la que más o menos se va admitiendo su posibilidad, su normalidad, casi casi su conveniencia.

Quedaba, pues, a medida que nos acercamos al final de la obra, destruir su carácter trágico, es decir, transmutar su género de tragedia en una comedia. Ello ocurre en dos momentos distintos, cada uno con su sorpresa, en la Esc. XII y en la Esc. XIII.

En la Esc. XII, dividida en dos partes, asistimos en la segunda de ellas al planteamiento del desenlace que realizan los dos personajes menos trágicos de toda la obra, Personajillo A y Personajillo B, que curiosamente han desempeñado un papel tan consustancial a la tragedia clásica como es el de Coro. Lourdes Ortiz se ríe del problema de un desenlace trágico de este modo:

Personajillo A - ¿Qué hacer con la adúltera?

Personajillo B - Muerte por lapidación.

Personajillo A - ¿Y con el hijo infiel?

Personajillo B - Muerte también.

Personajillo A - El suicidio, por ejemplo.

Personajillo B - El suicidio siempre es bueno para estos casos: es limpio, es discreto, es oportuno y además es elegante. En todas las épocas ha habido héroes suicidas.

Personajillo A - Romeo y Julieta.

Personajillo B - Nerón.

Personajillo A - Sócrates.

P Personajillo B - Luis de Baviera.

Personajillo A - Agustina de Aragón.

Personajillo B - No. Agustina de Aragón no.

Personajillo A - Es cierto. Me dejaba llevar por el ritmo. Pero sí Madame Butterfly.

Personajillo B - Sí, en el Japón es una costumbre completamente establecida. Personajillo A - ¿Y Fedra?

Personajillo B - ¿Qué Fedra?

Personajillo A - La de Eurípides, la de Séneca. Todas tuvieron una muerte honrosa. Y los dioses, como es debido, castigaron también a Hipólito. Y eso que siempre había dicho "no". En nuestro caso es mucho más sencillo. ¡Fedra 
debe morir!

Personajillo B - ¡Hipólito debe morir!

Personajillo A - Oye, pero ya no se lleva.

Personajillo B - ¿El qué?

Personajillo A - La muerte trágica, la muerte por amor. Tristán... Tal vez debería morir Teseo. Al fin y al cabo es deber del viejo ceder el sitio al joven. Personajillo B - ¿Y si mueren los tres? A mi me gustan los finales terribles, apoteósicos, llenos de lagrimas, de grititos desaforados y con mucha sangre. Personajillo A - Además ya lo han pasado suficientemente bien. No es justo que en este valle de lágrimas, adonde venimos todos a sufrir, se produzcan excepciones. (59-60)

Sigue un largo debate de este curioso Coro, y llegamos a la Esc. XIII y última, con el desenlace más feliz que hubiéramos podido imaginar:

Fedra - Enona... ¿A qué día de la semana estamos hoy? Cada vez soy más distraída.

Enona - A jueves. Y como es jueves hoy le toca a...

Fedra - ¡A Hipólito! ¡Qué tonta soy, he encargado alhelíes y a él le enferman los alhelíes! Con esto del calendario, me armo un lío. Manda corriendo que los retiren. El sabe que los alhelíes son la flor favorita de Teseo y podría molestarle.

Enona - El lunes pasado también te equivocaste con la cena. Teseo aborrece el pescado.

Fedra - Sí, pero eso no fue culpa mía sino tuya. Cambiaron sus días sin avisarme. Yo ya me había habituado a que los lunes le corresponden a Hipólito. Por lo general sus amigos ese día duermen la resaca del fin de semana y prácticamente no hacen nada interesante. Enona, ¿sabes que Hipólito ha prometido presentarme a sus amigos? Cualquiera de estas noches vendrá Teramenes. Me habla tanto de él que ya casi lo conozco como si yo misma fuera Hipólito. Es un muchacho encantador, sensible, delicado, inteligente. Hipólito lo adora y yo ya sabes que adoro lo que adora Hipólito.

Enona - Donde caben tres, caben cuatro. Esperaremos que a Teramenes le gusten también los alhelíes.

Fedra - ¡Ay, dueña! Soy la mujer más afortunada de la tierra. ¿Te acuerdas hace sólo un mes cuando todo parecía imposible y yo estuve muerta? (63-64).

Esta reescritura de Lourdes Ortiz es buen testimonio de que los recursos inmanentes en las tragedias y en las comedias de los grandes clásicos de Grecia y de Roma carecen por completo de límites para la inspiración. 


\section{Bibliografía}

Lavagnini, R. (2003), «Fedra al cinema», Dioniso n. s. 2: 242-245.

Mariño Sánchez-Elvira, Rosa M. (1997), "Teseo, Fedra e Hipólito en el cine”, Est. Clás. 39: 111-125.

Mariño Sánchez-Elvira, R. M. (1997), “Fedra (M. Mur Oti, 1956)”, Metakinema www. metakinema.es/metakineman0s1a1.html

Ortiz, L. (1992), Antes de la batalla. Barcelona: Editorial Planeta.

Ortiz, L. (2013), Fedra. Madrid: Ediciones Irreverentes.

Pociña, A. López, A. (2008), Fedras de ayer y de hoy. Teatro, poesía, narrativa y cine ante un mito clásico. Granada: Universidad de Granada.

Pociña, A. López, A. (2016), Otras Fedras. Nuevos estudios sobre Fedra e Hipólito en el siglo XX. Granada, Editorial Universidad de Granada: 11-27.

Racine, J. (1931), Oeuvres. Tome Quatrième. Dubech, L. (ed.). Paris: La Cité des Livres.

Racine, J. (1944), Fedra. Andrómaca. Británico. Ester. Trad. Lamarque, L. Buenos Aires; Editorial Losada.

Racine, J. (1982), Andrómaca. Fedra. Intr., trad. y notas de Carlos Pujol. Barcelona: Editorial Planeta.

Racine, J. (1999), Andrómaca. Fedra. Náñez, E. (ed.). Trad. Fernández Lladó, M. D. Madrid: Ediciones Cátedra.

Ragué Arias, M. J. (1992), Lo que fue Troya. Los mitos griegos en el teatro español actual. Madrid, Asociación de Autores de Teatro: 129-134.

Rubino, M. (2009), "Margarita Liberaki", in Rubino, M., Fedra Per mano femminile. Genova, Il melangolo: 67-73.

Salvador Ventura, F. (2008), “Filmando Fedra en España (Manuel Mur Oti, 1956) y Francia (Jules Dassin, 1962)”, in Pociña, López 2008: 503-524. 